\title{
Inferior Turbinate Reduction during Rhinoplasty: Is There Any Effect on Rhinitis Symptoms?
}

\author{
João Pedro T. Garcia1(- Bianca H. de Moura2(- Vinícius H. Rodrigues ${ }^{3(-)}$ Manoela A. Vivan $^{3(0)}$ \\ Simone M. de Azevedo ${ }^{3(\infty)}$ José Eduardo L. Dolci ${ }^{4}$ Raphaella Migliavacca ${ }^{5}{ }^{\circledR}$ Michelle Lavinsky-Wolff ${ }^{5}$
}

${ }^{1}$ Graduate Program in Surgery, Universidade Federal do Rio Grande do Sul (UFRGS), Porto Alegre, RS, Brazil

2 Otolaryngology Service, Hospital Mãe de Deus, Porto Alegre, RS, Brazil

Address for correspondence João Pedro Tedesco Garcia, MD, Av. Diário de Notícias, 1624/603, torre 2, 90810-080 - Porto Alegre,

${ }^{3}$ School of Medicine, UFRGS, Porto Alegre, RS, Brazil

${ }^{4}$ Otolaryngology Service, Santa Casa de Misericórdia de São Paulo, São Paulo, SP, Brazil

5 Otolaryngology Service, Hospital de Clínicas de Porto Alegre (HCPA), Porto Alegre, RS, Brazil

Int Arch Otorhinolaryngol 2022;26:e111-e118.

\begin{abstract}
Introduction Inferior turbinate surgery is often performed concomitantly with rhinoseptoplasty. As inferior turbinates play a major role in allergic rhinitis, it seems reasonable to suggest that inferior turbinate surgery reduces allergy.

Objective To assess the impact of nasal turbinate surgery on non-obstructive allergic symptoms (nasal discharge, sneezing, pruritus, and allergic conjunctivitis) and on the use of allergic medication in patients with allergic rhinitis undergoing rhinoseptoplasty. Methods Secondary analysis of aggregated data from two randomized controlled trials. Participants with allergic rhinitis aged $\geq 16$ years were recruited. Data from two groups were analyzed: patients with rhinoseptoplasty and concomitant turbinate reduction (intervention group) and patients with rhinoseptoplasty only (control group). The 90-day postoperative frequency of non-obstructive allergic symptoms and of nasal steroid and oral antihistamine use were analyzed.

Results A total of 100 patients were studied. The groups were similar in terms of allergic symptom intensity and mean age. The frequency of non-obstructive allergic symptoms decreased 90 days postoperative in both groups $(p<0.01)$. There was no difference between the groups in the frequency of non-obstructive allergic symptoms

Keywords

- turbinates

- rhinoplasty

- rhinitis

- allergic

- randomized controlled trial

- steroids at 90 days $(p=0.835)$. Topical nasal steroid and oral histamine antagonist use decreased in the intervention group at 90 days $(p<0.05)$.

Conclusions Ninety days after the surgery, turbinate reduction performed in association with rhinoseptoplasty did not reduce the frequency of non-obstructive allergic symptoms more than rhinoplasty alone. However, the observed decrease in nasal steroid and oral antihistamine use suggests an impact of turbinate reduction on medication use in patients with allergic rhinitis undergoing rhinoseptoplasty. Trial Registration ClinicalTrials.gov database (NCT01457638 and NCT02231216).
\end{abstract}

received

August 10, 2020

accepted

December 8, 2020

published online

August 5, 2021
DOI https://doi.org/ 10.1055/s-0041-1726046. ISSN 1809-9777. (c) 2021. Fundação Otorrinolaringologia. All rights reserved.

This is an open access article published by Thieme under the terms of the Creative Commons Attribution-NonDerivative-NonCommercial-License, permitting copying and reproduction so long as the original work is given appropriate credit. Contents may not be used for commercial purposes, or adapted, remixed, transformed or built upon. (https://creativecommons.org/ licenses/by-nc-nd/4.0/)

Thieme Revinter Publicações Ltda., Rua do Matoso 170, Rio de Janeiro, RJ, CEP 20270-135, Brazil 


\section{Introduction}

Inferior turbinate surgery, which is a common nasal procedure, ${ }^{1-3}$ is indicated in patients with nasal obstruction associated with turbinate hypertrophy when nonsurgical strategies fail. It is commonly performed in association with procedures to correct other causes of nasal obstruction, deviated nasal septum, and internal valve stenosis. ${ }^{4-6}$ Rhinoseptoplasty is also often performed concomitantly with inferior turbinate surgery with the aim of preserving the total breathing area which is surgically reduced, even though there is no evidence of efficacy regarding this aspect. ${ }^{7-12}$

Allergic rhinitis (AR) is one of the main causes of turbinate enlargement. ${ }^{13}$ It is characterized by hypersensitivity induced by immune-mediated inflammation resulting from the exposure of the nasal mucosa to specific allergens. ${ }^{4,14,15}$ Symptoms of AR include rhinorrhea, nasal obstruction, sneezing, and postnasal drip that resolve spontaneously or following treatment. ${ }^{15}$ The inferior turbinate mucosa plays a central role in the pathophysiology of AR. ${ }^{16,17}$ The continuous allergic process causes engorgement of the turbinate tissue, producing obstructive symptoms. In addition, the inflammatory process affecting the turbinate epithelium and submucosa has also been linked to non-obstructive symptoms such as nasal secretion, discharge, and sneezing. ${ }^{16}$

Considering the major role played by the inferior turbinates in AR, it would be fair to hypothesize that surgical reduction of the tissue affected by inflammation might curtail the allergic process, in addition to increasing nasal patency. ${ }^{15,16}$ However, the literature still lacks controlled studies investigating this topic. The high prevalence of AR, which may affect up to $40 \%$ of the world population, with an economic impact close to US\$ 4.5 billion reported in the United States, ${ }^{14}$ warrants the search for treatment alternatives/strategies. Therefore, the present study aims to evaluate the impact of inferior turbinate surgery on non-obstructive allergic symptoms (NOAS) in patients with AR.

\section{Materials and Methods}

We performed a secondary analysis of unpublished data from two double-blind randomized controlled trials (RCTs) previously performed by our research group to evaluate the clinical impact of inferior turbinate reduction on the quality of life (QoL) of patients undergoing primary rhinoseptoplasty. ${ }^{9,10}$ These RCTs were designed to measure the relative change in QoL scores obtained with the validated Brazilian Portuguese version of the Nasal Obstruction Symptom Evaluation (NOSE-p) scale. ${ }^{18}$

The present secondary analysis was granted approval by the Research Ethics Committee at our institution (number 20180109), and investigators signed a nondisclosure agreement for the use of secondary data.

\section{RCT Sample and Protocol}

Details of the RCTs have been described elsewhere. ${ }^{9,10}$ Briefly, patients with an existing diagnosis of AR were recruited at the ear, nose, and throat (ENT) outpatient clinic (Facial Plastic Surgery Division, Otology and Head \& Neck Surgery) of a tertiary university hospital (Hospital de Clínicas de Porto Alegre) in southern Brazil. Individuals aged $\geq$ 16 years, with indication for primary rhinoseptoplasty for functional and/or esthetic reasons were eligible. The exclusion criteria were previous nasal surgery, nasal obstruction resulting strictly from inferior turbinate enlargement, and/or concomitant surgical procedures, such as functional endoscopic sinus surgery, adenoidectomy, blepharoplasty, or otoplasty.

In the study by Lavinsky-Wolff et al., ${ }^{9} 50$ patients were randomized to receive submucosal electrocauterization of the inferior turbinates ( 25 patients) associated with rhinoseptoplasty, or rhinoseptoplasty only (25 patients). In the study by De Moura et al., ${ }^{10} 50$ patients were randomized to receive endoscopic partial inferior turbinectomy associated with rhinoseptoplasty (25 patients), or rhinoseptoplasty only (25 patients). Both studies employed a randomization sequence generated using a web-based tool (http://randomization.com/) by an independent investigator. A 1:1 allocation ratio was used to randomize patients with or without inferior turbinate surgery with blocks including 4 to 6 participants. Investigators involved in the recruitment and evaluation of the patients were blinded to allocation sequence.

In both RCTs, participants were evaluated pre and postoperatively using a standard protocol administered by trained investigators who were blinded to the study intervention. Evaluations were performed preoperatively and at 7 , 30,60 , and 90 days postoperatively. The diagnosis of AR was based on the presence of two or more of the following symptoms (as stated in the 2008 Allergic Rhinitis and its Impact on Asthma [ARIA] guidelines): watery rhinorrhea, sneezing, nasal obstruction, nasal pruritus, and allergic conjunctivitis for more than 1 hour on most days. ${ }^{15}$ Patients were asked about symptoms of AR at all follow-up visits, and were classified according to symptom intensity and frequency into an intermittent or persistent category and a mild or moderate/severe category according to the ARIA guidelines. ${ }^{15}$

Starting on postoperative day 30 , a topical nasal steroid (budesonide 100 micrograms twice a day) was prescribed for 30 days to all patients with mild and persistent symptoms and to those with moderate/severe symptoms. ${ }^{15}$ From postoperative day 60 to 90 , budesonide 100 micrograms once a day was prescribed if symptoms improved, or budesonide 200 micrograms twice a day if symptoms persisted. All patients were advised to use $\mathrm{h} 1$-antihistamines as required.

At baseline, the NOSE-p scale ${ }^{18}$ was administered to all patients to assess outcomes in nasal obstruction in the trials. A score of 0 indicates no problems with nasal obstruction, and a score of 100 indicates the worst possible problems with nasal obstruction.

At all follow-up visits, the patients answered a standardized questionnaire about medications used for AR. The questionnaire included questions about whether the patient was using topical nasal corticosteroids and whether there 


\section{Lavinsky-Wolff et al. ${ }^{9}$ \\ NCT01457638}
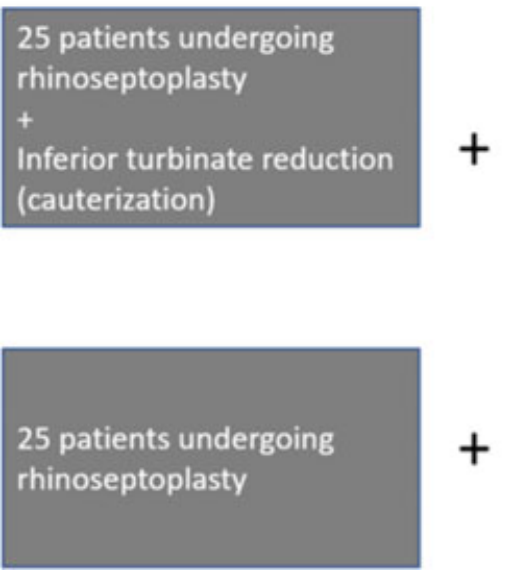

De Moura et al. ${ }^{10}$

NCT02231216

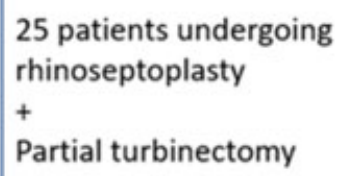

Partial turbinectomy

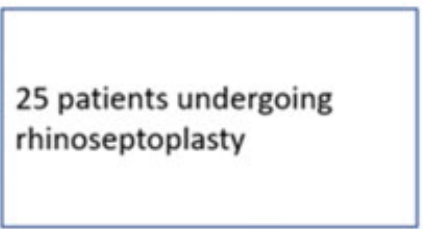

Present study
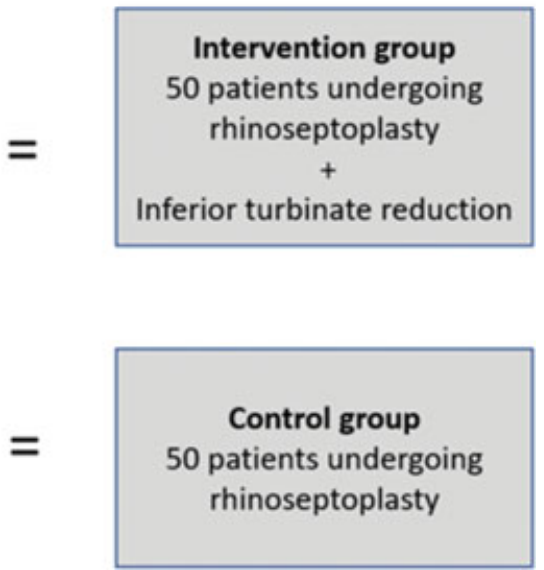

Fig. 1 Study protocol.

was a need for oral antihistamine medication in the past 30 days.

\section{Assessment of NOAS}

In the present study, NOAS were evaluated in RCT participants. As a first step, data from each trial were analyzed separately. In the turbinate surgery group (which included 50 patients), 25 patients underwent submucosal electrocauterization and 25 patients underwent partial inferior turbinectomy. These data were combined for analysis, with patients who had undergone inferior turbinate surgery forming an intervention group and patients receiving only rhinoseptoplasty analyzed as a control group ( - Fig. 1). Nonobstructive allergic symptoms at 90 days were compared between the groups. Also, NOAS recorded before surgery were compared with NOAS at 90 days in both groups.

\section{Primary Outcome Measure}

Patients were asked about clinical symptoms of AR, as stated in the ARIA guidelines, ${ }^{15}$ at all follow-up visits using a standard protocol administered by trained investigators who were blinded to the study intervention. Non-obstructive allergic symptoms were defined as discharge, sneezing, itching, or allergic conjunctivitis lasting at least 1 hour and occurring on most days.

The main outcome measure in the present study was a composite variable defined as the presence of one or more NOAS at baseline and 90 days postoperatively.

\section{Secondary Outcome Measure}

The frequency of topical nasal steroid and of oral antihistamine use 90 days postoperatively was analyzed as a secondary outcome measure.

\section{Statistical Analysis}

Statistical analysis was performed with IBM SPSS Statistics for Windows, Version 20.0 (IBM Corp., Armond, NY, USA). Data were presented as means, standard deviation, number or percentage. Statistical significance was established at $p=0.05$. Continuous variables were compared using the Student $t$-test. The chi-squared test was used for comparison of non-parametric variables. The frequency of allergic symptoms at 90 days postoperatively was analyzed using a Poisson regression model for robust variance adjusted for the use of topical nasal steroid and oral antihistamine. A generalized estimating equation (GEE) was used to compare the frequency of each allergic symptom preoperatively and at 90 days postoperatively.

\section{Results}

One hundred patients were analyzed, 50 in the intervention group and 50 in the control group ( - Fig. 1). In each group, 3 patients were lost to follow-up, adding to a total of 6 patients (6\%). Preoperatively, most patients reported moderate/ severe allergic symptoms and nasal obstruction. The mean age was $34 \pm 13$ years in the intervention group and $34 \pm 16$ years in the control group. There were no differences in the mean NOSE score, age, sex, years of schooling, nasal obstruction, or intensity of ARIA symptoms between the groups at baseline (-Table $\mathbf{1}$ ).

Septal deviation was diagnosed in 93 participants (93\%) 48 in the intervention group and 45 in the control group (-Table 1). The groups were similar regarding the severity of septal deviation. Patients were submitted to rhinoseptoplasty regardless of the presence of septal deviation to harvest cartilage grafts for the procedure.

When each allergic symptom was analyzed independent$1 y$, a reduction in the intragroup frequency was noted 90 days postoperatively versus preoperatively $(p<0.01)$ for all symptoms, except allergic conjunctivitis (intervention group, $p=0.112$; control group, $p=0.253$ ). There was no difference in the frequency of each symptom between the groups at 90 days (-Table 2). Regarding patients with seasonal complaints, there was no difference between the groups in the number of patients with exacerbations either at baseline $(p=0.389)$ or 90 days postoperatively $(p=0.881)$. 
Table 1 Characteristics of the intervention and control groups

\begin{tabular}{|c|c|c|}
\hline Characteristic & $\begin{array}{l}\text { Intervention } \\
\text { group }(n=50)\end{array}$ & $\begin{array}{l}\text { Control } \\
\text { group }(n=50)\end{array}$ \\
\hline $\begin{array}{l}\text { Mean age (SD), } \\
\text { years }\end{array}$ & $34(13)$ & $34(16)$ \\
\hline $\begin{array}{l}\text { Female gender, no. } \\
(\%)\end{array}$ & $27(54)$ & $26(52)$ \\
\hline \multicolumn{3}{|c|}{ Years of schooling, no. (\%) } \\
\hline$\leq 8$ & $13(26)$ & $18(36)$ \\
\hline $9-11$ & $24(48)$ & $22(44)$ \\
\hline$\geq 12$ & $13(26)$ & $10(20)$ \\
\hline \multicolumn{3}{|l|}{ NOAS } \\
\hline Sneezing & $23(46)$ & $23(46)$ \\
\hline Discharge & $17(34)$ & $25(50)$ \\
\hline Itching & $20(40)$ & $24(48)$ \\
\hline $\begin{array}{l}\text { Allergic } \\
\text { conjunctivitis }\end{array}$ & $9(18)$ & $12(24)$ \\
\hline Nasal obstruction & $47(94)$ & $48(96)$ \\
\hline $\begin{array}{l}\text { Nose score, mean } \\
\text { (SD) }\end{array}$ & $70.2(24.4)$ & $78.7(16.4)$ \\
\hline \multicolumn{3}{|c|}{ ARIA symptom intensity, no. (\%) } \\
\hline Mild & $5(10.2)$ & $4(8.2)$ \\
\hline Moderate-severe & $45(89.8)$ & $46(91.8)$ \\
\hline $\begin{array}{l}\text { Seasonal symp- } \\
\text { toms, no. (\%) }\end{array}$ & $36(72)$ & $34(68)$ \\
\hline \multicolumn{3}{|l|}{ Worst in, no. (\%) } \\
\hline Winter & $21(42)$ & $22(44)$ \\
\hline Spring & $7(14)$ & $7(14)$ \\
\hline Other & $8(16)$ & $5(10)$ \\
\hline $\begin{array}{l}\text { Use of topical nasal } \\
\text { steroid at baseline, } \\
\text { no. (\%) }\end{array}$ & $22(44)$ & $24(48)$ \\
\hline $\begin{array}{l}\text { Deviated septum, } \\
\text { no }(\%) \\
\text { Amount nasal ob- } \\
\text { struction caused by } \\
\text { deviated septum, } \\
\text { no. }(\%)\end{array}$ & $48(96)$ & $45(90)$ \\
\hline$<25 \%$ & $1(2)$ & 0 \\
\hline $25-50 \%$ & $4(8)$ & $7(14)$ \\
\hline $50-75 \%$ & $14(28)$ & $14(28)$ \\
\hline$>75 \%$ & $29(58)$ & $24(48)$ \\
\hline
\end{tabular}

Abbreviations: ARIA, Allergic Rhinitis and its impact on Asthma; NOAS, non-obstructive allergic symptoms; NOSE, Nasal Obstruction Symptom Evaluation; SD, standard deviation.
Both the use of topical steroids and the presence of NOAS were similar in the two groups prior to the surgery. At 90 days, the groups remained similar regarding nasal obstruction $(p=0.769)$ as well as regarding NOSE scores $(p=0,769)$. The same was true for NOAS at 90 days $(p=0.835)$, even after adjustment for topical nasal steroid and oral antihistamine use $(p=0.899)$ ( - Table 3 ).

At 3 months postoperatively, nasal spray use was less frequent in the intervention group versus controls (34\% versus $59 \%$ respectively; $p=0.014$ ). A protective effect (relative risk [RR]: 0.35 ; 95\%CI: $0.151-0.810$ ) was observed for steroid nasal spray in the intervention group. The frequency of oral antihistamine use was also lower in the intervention versus the control group ( $2 \%$ versus $23 \% ; p=0.016$ ). As a result, a protective effect for medication use was detected in the intervention group (RR: $0.145 ; 95 \% \mathrm{Cl}: 0.030-0.699$ ) (-Table 3).

\section{Discussion}

The present study is the third by our group evaluating the impact of inferior turbinate surgery in patients submitted to rhinoseptoplasty. Lavinsky-Wolff et al., ${ }^{9}$ in 2013, and De Moura et al., ${ }^{10}$ in 2018, focused on QoL related to nasal obstruction measured by the NOSE scale. In the present study, a secondary analysis was performed by aggregating data from these two previous RCTs, focusing on NOAS. In addition to improvement in nasal obstruction, patients undergoing inferior turbinate surgery also often report improvement in all AR symptoms. However, analysis of this relationship is complex and confounded by topical steroid use and by the difficulty in assessing these symptoms objectively.

To the best of our knowledge, the present study is the first to evaluate in a controlled manner, albeit based on secondary data, the impact of nasal turbinate surgery on NOAS in patients undergoing rhinoseptoplasty. The data analyzed in this study were produced with randomization and blinding of participants and investigators and having a control group of patients undergoing rhinoseptoplasty without inferior turbinate reduction. Previous RCTs ${ }^{19,20}$ have compared several interventions for turbinate reduction with the aim of evaluating the impact on NOAS and nasal obstruction, and noted improvement in NOAS as well as obstruction symptoms.

Table 2 Frequency of non-obstructive allergic symptoms in the intervention and control groups prior to surgery and 90 days postoperatively

\begin{tabular}{|l|l|l|l|l|l|l|l|}
\hline Symptom, $\mathbf{n}(\%)$ & \multicolumn{4}{|l|}{ Intervention group $(\boldsymbol{n}=\mathbf{5 0})$} & \multicolumn{2}{l|}{ Control group $(\boldsymbol{n}=\mathbf{5 0})$} & \\
\hline & Preoperative & 90 days & $p$ time & Preoperative & 90 days & $p$ time & $p$ 90 days \\
\hline Sneezing & $23 / 50(46)$ & $7 / 47(15)$ & $<0.01$ & $23 / 50(46)$ & $11 / 47(23)$ & $<0.01$ & 0.216 \\
\hline Itching & $20 / 50(40)$ & $9 / 47(19)$ & $<0.01$ & $24 / 50(48)$ & $10 / 47(20)$ & $<0.01$ & 0.783 \\
\hline Discharge & $17 / 50(34)$ & $11 / 47(23)$ & $<0.01$ & $25 / 50(50)$ & $8 / 47(17)$ & $<0.01$ & 0.843 \\
\hline Allergic conjunctivitis & $12 / 50(24)$ & $7 / 47(15)$ & 0.137 & $9 / 50(18)$ & $5 / 47(10)$ & 0.253 & 0.128 \\
\hline
\end{tabular}

Generalized estimating equation (GEE) for comparisons between the groups. ( $p$ time, intragroup difference in pre and postoperative frequency); ( $p$ 90 days, between-group difference at 90 days postoperatively). 
Table 3 Frequency of participants with one or more non-obstructive allergic symptoms and medication use at 90 days postoperatively

\begin{tabular}{|l|l|l|l|}
\hline Variable, $\boldsymbol{n}(\%)$ & Intervention group $(\boldsymbol{n}=\mathbf{4 7})$ & Control group $(\boldsymbol{n}=47)$ & $\boldsymbol{p}$ \\
\hline One or more NOAS & $20 / 47(42)$ & $21 / 47(44)$ & $0.835^{\mathrm{a}} / 0.899^{\mathrm{b}}$ \\
\hline Topical nasal steroid (yes) & $16 / 47(34)$ & $28 / 47(59)$ & $0.014^{\mathrm{a}} / 0.037^{\mathrm{b}}$ \\
\hline Oral antihistamine (yes) & $2 / 47(4)$ & $10 / 47(20)$ & $0.016 /{ }^{\mathrm{a}} 0.030^{\mathrm{b}}$ \\
\hline
\end{tabular}

Abbreviation: NOAS, non-obstructive allergic symptoms.

p: Poisson regression for robust variables.

aunadjusted.

badjusted for steroid and oral antihistamine use. $p<0.05$, Pearson $x^{2}$.

An important finding of the present study was a lower frequency of topical nasal steroid use in the intervention group observed 90 days after the procedure. The use of steroids is a potential confounding factor. Nevertheless, for ethical reasons, the medication was provided to patients with persistent or moderate-severe intensity AR symptoms. To control for this potential bias, a single prescription protocol was used for all participants in both RCTs, and contemplated in our regression model.

Also noteworthy was the lower frequency of antihistamine use at 90 days postoperatively in the intervention group. The use of this medication is also a potential confounding factor; however, antihistamines were provided to participants, as well as nasal steroids. Patients were guided to use the medication in the presence of symptoms, with the frequency of use informed and recorded during the followup consultations.

Measuring the efficacy of an intervention in multifactorial diseases is challenging and further complicated by the use of one or several medications that directly impact symptoms, producing changes in the intensity of clinical complaints. ${ }^{9}$ For that reason, the RCTs on which the present study was based were designed as pragmatic trials, which measured effectiveness and included real-world patients recruited from an outpatient clinic, influenced by aspects of their usual routine.

A possible explanation for the impact of inferior turbinate surgery on NOAS could be found in the pathophysiology of AR. Turbinate epithelium is a key site for the genesis of allergic reactions. ${ }^{13}$ Consequently, tissue reduction might lead to fewer/less intense symptoms. ${ }^{16,17}$ Apparently, resection of autonomic nervous in the submucosa, which are responsible for the control of vessel engorgement and mucus and immunoglobulin production, leads to improvement in sneezing and rhinorrhea. ${ }^{16}$ The replacement with scar tissue contributes to the improvement in discharge. ${ }^{16}$ In a study comparing the histopathological characteristics of two groups with AR submitted to turbinectomy, Lukka et al. ${ }^{13}$ found restoration of a histological pattern that was similar to that of patients without the disorder.

There is no consensus regarding the ideal technique for inferior turbinate surgery. ${ }^{2}$ The most widely used techniques rely on "cold" volume reduction, such as partial turbinectomy, and on thermal methods, such as electrocauterization. ${ }^{21}$ The underlying rationale is usually to avoid aggressive reductions in tissue volume to prevent empty nose syndrome. ${ }^{2,22,23}$ In the present study, no differences were detected in the frequency of NOAS at 90 days regardless of the type of technique employed for turbinate reduction.

The improvement in NOAS detected in our population supports previous findings from the literature. Mori et al. ${ }^{16,24}$ showed evidence of improvement not only in nasal obstruction following submucosal turbinectomy, but also in sneezing, discharge, and itching. Chen et al. ${ }^{19}$ and Caffier et al. $^{25}$ reported similar results. More recently, Hamerschmidt et al. ${ }^{26}$ studied a cohort including two groups with inferior turbinate hypertrophy undergoing turbinoplasty, one with NOAS and the other with nasal obstruction. The group with allergy symptoms had significant reduction of NOAS after turbinoplasty, as compared with the preoperative period. It should be noted, however, that none of these studies involved randomization of participants and blinding of participants and investigators.

There was no difference in the frequency of NOAS between our groups at 90 postoperative days. This might be linked to the increased frequency of clinical treatment of AR in the control group. To control for this potential confounding factor, we performed an analysis adjusted for topical steroid and oral antihistamine use. Another possible explanation for the improvement in NOAS is the potential influence of septal deviation treatment on allergic symptoms. According to Kim et al., ${ }^{27}$ septoplasty may have a positive impact on NOAS in patients with a diagnosis of AR. That study reported an improved postoperative score obtained with Rhinasthma, ${ }^{28}$ a validated instrument for assessment of AR and asthma, in a group submitted to septoplasty associated with submucosal turbinoplasty in comparison to a group submitted only to submucosal turbinoplasty. In theory, normalization of air flow could reduce inflammation in the nasal cavities, impacting NOAS.

Interestingly, in our current analysis, we found that patients undergoing turbinate surgery used fewer topical corticosteroids and fewer antihistamines 90 days after the procedure. The latter was not evident in the data from the individual trials that make up our study ${ }^{9,10}$ (-Fig. 2). It is possible that these patients were actually using these medications for nasal obstruction, and not for NOAS, which may have shown more improvement in the inferior turbinate group. We did not include measurements of nasal patency, so it is also possible that discrepancies in acoustic 


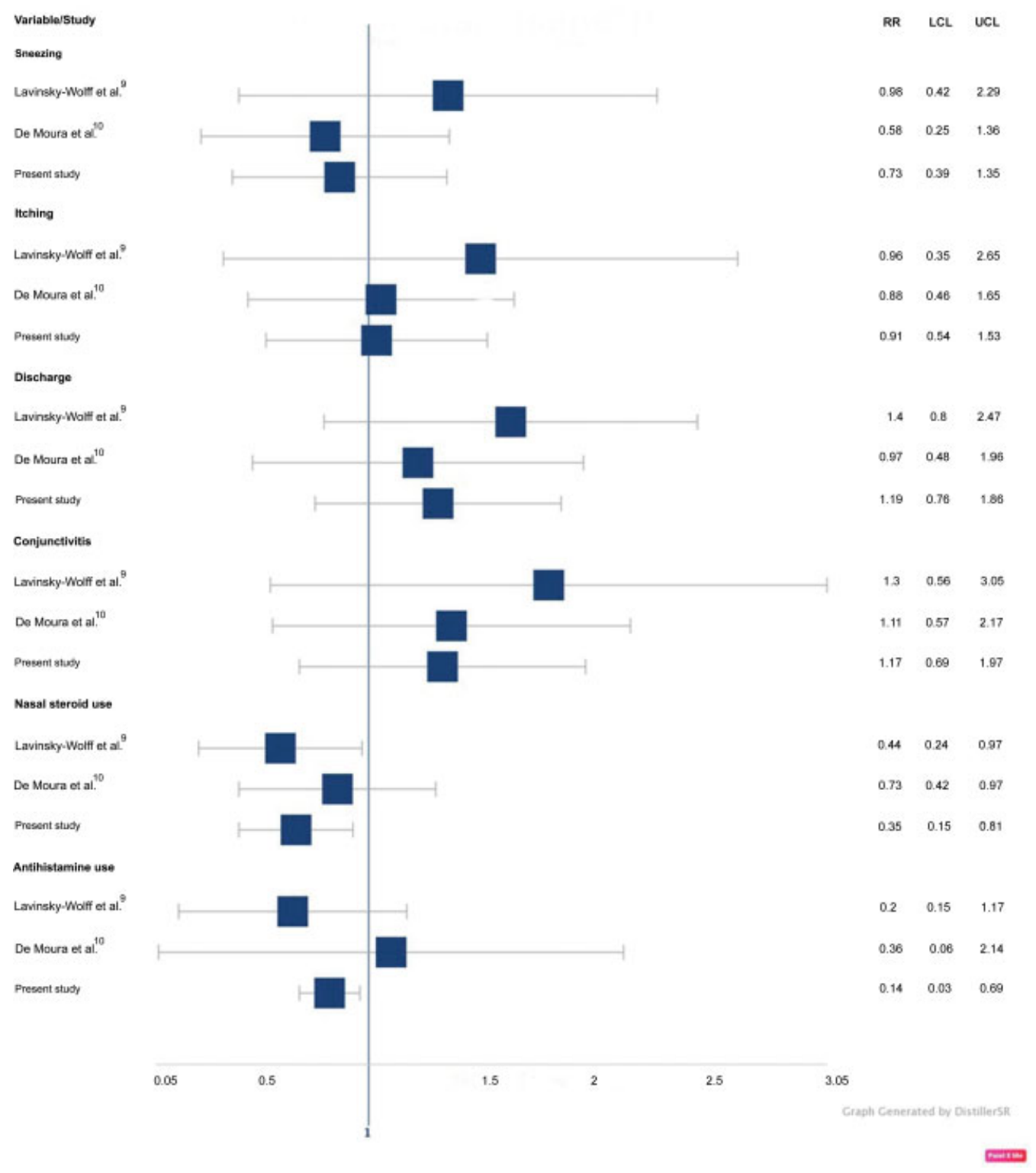

Fig. 2 Forest plot showing risk of symptoms and medication use 90 days after nasal turbinate reduction.

rhinomanometry could have some influence in our findings. It is also possible that turbinate surgery could have accelerated the clinical improvement of AR symptoms; however, this contrasts with the lack of between-group difference in NOAS observed in our study.

Despite the strict methodological criteria employed in the present study, some limitations must be addressed. The RCTs whose data we analyzed were designed for assessment of nasal obstruction-related QoL. Information regarding NOAS was collected using the ARIA guidelines ${ }^{15}$ questionnaire designed for clinical diagnosis of AR, but visual/verbal analogue scales were not used to gauge the intensity of symptoms. Also, we did not use any laboratory test for AR diagnosis. Our patient follow-up was limited to 90 days after the procedure. However, it is generally assumed that at 3 months there is maximal scar tissue contraction; therefore, if no difference is NOAS was detected at 90 days, it seems unlikely that this difference would emerge in the long term. ${ }^{10}$ Another issue may be the sample size, which was originally calculated to detect differences in the NOSE scale, but not in the AR outcomes. Given the frequencies of NOAS that were observed, our study is powered to detect a $38 \%$ reduction in the incidence of NOAS (assuming a baseline incidence of $21 / 47$, one-tailed chi-square test). Because the incidences in the control and intervention groups were virtually the same, we believe that our observation is correct. However, a larger study would be required to corroborate our findings.

\section{Conclusion}

Turbinate reduction performed in association with rhinoseptoplasty did not reduce the frequency of non-obstructive allergic symptoms 90 days after the procedure more than rhinoplasty alone. However, the observed decrease in nasal 
steroid and oral antihistamine use suggests an impact of turbinate reduction on medication use in patients with AR undergoing rhinoseptoplasty.

\section{Informed Consent}

Informed consent was obtained from all individual participants included in the study.

\section{Ethical Approval}

All procedures performed in studies involving human participants were in accordance with the ethical standards of the national research committee of our institution (Research Ethics Committee at Hospital de Clínicas de Porto Alegre (HCPA), number 20180109) and with the 1964 Helsinki declaration and its later amendments or comparable ethical standards.

\section{Data Availability}

All relevant data are within the paper.

\section{Funding}

This research received no specific grant from any funding agency in the public, commercial, or not-for-profit sectors.

\section{Conflict of Interests}

The authors declare that there is no conflict of interests.

\section{References}

1 Leong SC, Eccles R. Inferior turbinate surgery and nasal airflow: evidence-based management. Curr Opin Otolaryngol Head Neck Surg 2010;18(01):54-59. Doi: 10.1097/MO0.0b013e328334db14

2 Veit JA, Nordmann M, Dietz B, et al. Three different turbinoplasty techniques combined with septoplasty: Prospective randomized trial. Laryngoscope 2017;127(02):303-308. Doi: 10.1002/ lary.26264

3 Passàli D, Lauriello M, Anselmi M, Bellussi L. Treatment of hypertrophy of the inferior turbinate: long-term results in 382 patients randomly assigned to therapy. Ann Otol Rhinol Laryngol 1999;108(06):569-575. Doi: 10.1177/000348949910800608

4 Brożek JL, Bousquet J, Agache I, et al. Allergic Rhinitis and its Impact on Asthma (ARIA) guidelines-2016 revision. J Allergy Clin Immunol 2017;140(04):950-958. Doi: 10.1016/j.jaci.2017.03.050

5 Passàli D, Passàli FM, Damiani V, Passàli GC, Bellussi L. Treatment of inferior turbinate hypertrophy: a randomized clinical trial. Ann Otol Rhinol Laryngol 2003;112(08):683-688. Doi: 10.1177/ 000348940311200806

6 Kim DH, Park HY, Kim HS, et al. Effect of septoplasty on inferior turbinate hypertrophy. Arch Otolaryngol Head Neck Surg 2008; 134(04):419-423. Doi: 10.1001/archotol.134.4.419

7 Downs BW. The inferior turbinate in rhinoplasty. Facial Plast Surg Clin North Am 2017;25(02):171-177. Doi: 10.1016/j. fsc.2016.12.003

8 Grymer LF. Reduction rhinoplasty and nasal patency: change in the cross-sectional area of the nose evaluated by acoustic rhinometry. Laryngoscope 1995;105(4 Pt 1):429-431. Doi: 10.1288/ 00005537-199504000-00017

9 Lavinsky-Wolff M, Camargo HL Jr, Barone CR, et al. Effect of turbinate surgery in rhinoseptoplasty on quality-of-life and acoustic rhinometry outcomes: a randomized clinical trial. Laryngoscope 2013;123(01):82-89. Doi: 10.1002/lary.23628
10 de Moura BH, Migliavacca RO, Lima RK, et al. Partial inferior turbinectomy in rhinoseptoplasty has no effect in quality-of-life outcomes: A randomized clinical trial. Laryngoscope 2018;128 (01):57-63. Doi: 10.1002/lary.26831

11 Grymer LF, Gregers-Petersen C, Baymler Pedersen H. Influence of lateral osteotomies in the dimensions of the nasal cavity. Laryngoscope 1999;109(06):936-938. Doi: 10.1097/00005537199906000-00018

12 Grymer LF, Hilberg O, Pedersen OF, Rasmussen TR. Acoustic rhinometry: values from adults with subjective normal nasal patency. Rhinology 1991;29(01):35-47

13 Lukka VK, Jacob TM, Jeyaseelan V, Rupa V. Do turbinate reduction procedures restore epithelial integrity in patients with turbinate hypertrophy secondary to allergic rhinitis? A histopathological study. Eur Arch Otorhinolaryngol 2018;275(06):1457-1467. Doi: 10.1007/s00405-018-4955-y

14 Brozek JL, Bousquet J, Baena-Cagnani CE, et al; Global Allergy and Asthma European Network Grading of Recommendations Assessment, Development and Evaluation Working Group. Allergic Rhinitis and its Impact on Asthma (ARIA) guidelines: 2010 revision. J Allergy Clin Immunol 2010;126(03):466-476. Doi: 10.1016/j.jaci.2010.06.047

15 Bousquet J, Khaltaev N, Cruz AA, et al; World Health Organization GA(2)LEN AllerGen. Allergic rhinitis and its impact on asthma (ARIA) 2008 update (in collaboration with the World Health Organization, GA(2)LEN and AllerGen). Allergy 2008;63(Suppl 86):8-160. Doi: 10.1111/j.1398-9995.2007. 01620.x

16 Mori S, Fujieda S, Igarashi M, Fan GK, Saito H. Submucous turbinectomy decreases not only nasal stiffness but also sneezing and rhinorrhea in patients with perennial allergic rhinitis. Clin Exp Allergy 1999;29(11):1542-1548. Doi: 10.1046/j.13652222.1999.00645.x

17 Chhabra N, Houser SM. The surgical management of allergic rhinitis. Otolaryngol Clin North Am 2011;44(03):779-795, xi. Doi: 10.1016/j.otc.2011.03.007

18 Stewart MG, Witsell DL, Smith TL, Weaver EM, Yueh B, Hannley MT. Development and validation of the Nasal Obstruction Symptom Evaluation (NOSE) scale. Otolaryngol Head Neck Surg 2004; 130(02):157-163. Doi: 10.1016/j.otohns.2003.09.016

19 Chen YL, Tan CT, Huang HM. Long-term efficacy of microdebriderassisted inferior turbinoplasty with lateralization for hypertrophic inferior turbinates in patients with perennial allergic rhinitis. Laryngoscope 2008;118(07):1270-1274. Doi: 10.1097/ MLG.0b013e31816d728e

20 Bakshi SS, Shankar Manoharan K, Gopalakrishnan S. Comparison of the long term efficacy of radiofrequency ablation and surgical turbinoplasty in inferior turbinate hypertrophy: a randomized clinical study. Acta Otolaryngol 2017;137(08):856-861. Doi: 10.1080/00016489.2017.1294764

21 Huang TW, Cheng PW. Changes in nasal resistance and quality of life after endoscopic microdebrider-assisted inferior turbinoplasty in patients with perennial allergic rhinitis. Arch Otolaryngol Head Neck Surg 2006;132(09):990-993. Doi: 10.1001/ archotol.132.9.990

22 Di Rienzo Businco L, Di Rienzo Businco A, Ventura L, Laurino S, Lauriello M. Turbinoplasty with quantic molecular resonance in the treatment of persistent moderate-severe allergic rhinitis: Comparative analysis of efficacy. Am J Rhinol Allergy 2014;28 (02):164-168. Doi: 10.2500/ajra.2014.28.3990

23 Coste A, Dessi P, Serrano E. Empty nose syndrome. Eur Ann Otorhinolaryngol Head Neck Dis 2012;129(02):93-97. Doi: 10.1016/j.anorl.2012.02.001

24 Mori S, Fujieda S, Yamada T, Kimura Y, Takahashi N, Saito H. Longterm effect of submucous turbinectomy in patients with perennial allergic rhinitis. Laryngoscope 2002;112(05):865-869. Doi: 10.1097/00005537-200205000-00016 
118 Turbinate Surgery and Allergic Rhinitis Garcia et al.

25 Caffier PP, Scherer H, Neumann K, Lück S, Enzmann H, Haisch A. Diode laser treatment in therapy-resistant allergic rhinitis: impact on nasal obstruction and associated symptoms. Lasers Med Sci 2011;26(01):57-67. Doi: 10.1007/s10103-010-0813-X

26 Hamerschmidt R, Hamerschmidt R, Moreira AT, Tenório SB, Timi JRR. Comparison of turbinoplasty surgery efficacy in patients with and without allergic rhinitis. Rev Bras Otorrinolaringol (Engl Ed) 2016;82(02):131-139. Doi: 10.1016/j.bjorl.2015.10.010
27 Kim YH, Kim BJ, Bang KH, Hwang Y, Jang TY. Septoplasty improves life quality related to allergy in patients with septal deviation and allergic rhinitis. Otolaryngol Head Neck Surg 2011;145(06): 910-914. Doi: 10.1177/0194599811424119

28 Baiardini I, Pasquali M, Giardini A, et al. Rhinasthma: a new specific QoL questionnaire for patients with rhinitis and asthma. Allergy 2003;58(04):289-294. Doi: $10.1034 / \mathrm{j} .1398-$ 9995.2003.00079.x 